\title{
Low Moisture Absorptive Epoxy Formulations for Gr/Ep Laminates
}

\author{
KING-FU LIN* and REN-JIE YEH \\ Institute of Materials Science and Engineering \\ National Taiwan University \\ Taipei, Taiwan 10617, Republic of China
}

\begin{abstract}
The incorporation of 2-undecyl-imidazole $\left(\mathrm{C}_{11} \mathrm{Z}\right)$ and chromium acetylacetonate $\left(\mathrm{Cr}\left(\mathrm{acac}_{3}\right)\right.$ additives into $\mathrm{N}, \mathrm{N}, \mathrm{N}^{\prime}, \mathrm{N}^{\prime}$-tetraglycidyl diaminodiphenylmethane (TGDDM)/diaminodiphenylsulfone (DDS) epoxy formulations was found to significantly decrease the moisture absorption of their prepared graphite/epoxy laminates. However, the same additions did not much affect the moisture absorption of the cured TGDDM/DDS neat resins. Thus, the former case was attributed to the processing effects in view of the fact that $C_{11} Z$ pre-reacting with TGDDM during lay-up process produced the ether-linkage polymer chains in the epoxy networks and raised the viscosity. The following compacting stage of laminates was believed to squeeze the small molecules such as unreacted TGDDM, DDS and Cr(acac) 3 , toward the surface of carbon fibers and increase the chance of $\mathrm{Cr}(\mathrm{acac})_{3}$ to block the hydroxyl groups in the epoxy networks produced by the reactions between TGDDM and DDS. Some evidence was provided to support the above hypothesis in this study.
\end{abstract}

\section{INTRODUCTION}

$\mathrm{O}$ rganotransition metal complexes have been frequently used as accelerators for curing epoxy resins (1-3). However, they were also reported to be able to enhance cured mechanical properties (4-6). In our laboratory, we have found that chromium acetylacetonate ( $\mathrm{Cr}\left(\mathrm{acac}_{3}\right)$ can interact with hydroxyl groups in the epoxy network formed by the reaction of epoxy groups with amine hydrogen and increase the fracture toughness $(7,8)$.

When $\mathrm{Cr}\left(\right.$ acac $_{3}$ was incorporated into $\mathrm{N}, \mathrm{N}, \mathrm{N}, \mathrm{N}^{\prime}$ tetraglycidyl diamino-diphenylmethane (TGDDM)/diaminodiphenylsulfone (DDS) epoxy formulations to prepare graphite/epoxy (Gr/Ep) laminates, the manufactured laminates did not have enough resin content because of low resin viscosity during the compaction stage of the laminating process. To overcome this problem, we have employed 2-undecyl-imidazole $\left(C_{11} Z\right)$ accelerator to pre-react with TGDDM epoxy resin and raise the viscosity before pressurizing the laminates (9). The resulting resin content was satisfactory and the incorporation of $\mathrm{Cr}$ (acac) $)_{3}$ in the epoxy formulations was also able to increase the interlaminar fracture toughness. Therefore, what we were in-

To whom correspondence should be addressed. terested in here was how those additives affect the hygrothermal fatigue of $\mathrm{Gr} / \mathrm{Ep}$ laminates.

St. Clair et al. have reported that the moisture resistance of epoxy resins could be improved by the addition of $\mathrm{Cr}(\mathrm{acac})_{3}(10)$. According to our previous study (8), each $\mathrm{Cr}(\mathrm{acac})_{3}$ molecule was able to block at least three hydroxyl groups by proton transfer in the epoxy network, presumably leading to the decrease of water absorption. On the other hand, $\mathrm{C}_{11} \mathrm{Z}$ additive alone reacted with TGDDM epoxy resins at about $120^{\circ} \mathrm{C}$, much lower than the main reaction temperature of TGDDM/DDS. The former reactions were found to begin with the adduction of epoxy groups to the $\mathrm{N}$ groups of imidazole, which then triggered the chainetherification (11). Thus, due to the fact that few hydroxyl groups are produced in the reactions of TGDDM $/ C_{11} Z$, we assumed that the incorporation of $\mathrm{C}_{11} \mathrm{Z}$ should also increase the moisture resistance of epoxy resins. Therefore, based on our perception, the moisture resistance ought to be much enhanced if both $\mathrm{Cr}(\mathrm{acac})_{3}$ and $\mathrm{C}_{11} \mathrm{Z}$ were incorporated into the epoxy formulations.

For comparison, in this study we also employed dicyandiamide (DICY) and boron trifluoride monoethylamine $\left(\mathrm{BF}_{3} \mathrm{MEA}\right)$ as curing accelerators in addition to $\mathrm{C}_{11} Z$. Their sole effect and combination effects with Cr(acac) ${ }_{3}$ on the moisture absorption of TGDDM/DDS epoxy resins and their prepared graphite/epoxy $(\mathrm{Gr} /$ Ep) laminates were investigated. 


\section{EXPERMIENTAL}

\section{Materials}

The epoxy resin used was Ciba-Geigy's MY 720 resin, which contains primarily TGDDM. The curing agent was Ciba-Geigy's HT 976 hardener, which con-

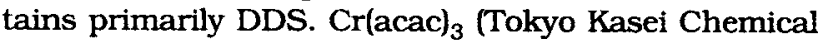
Industries), $\mathrm{C}_{11} Z$ (Epocone Chemical), DICY (Epocone Chemical) and $\mathrm{BF}_{3} \mathrm{MEA}$ (Allied Chemical) were used as additives. The carbon fiber reinforcement for the laminates was Torayca T700SC, a continuous high strength PAN-based fiber.

\section{Sample Preparation}

The epoxy formulation containing TGDDM and DDS in stoichiometric ratio is represented as TGDDM/DDS, whereas those of TGDDM/DDS incorporating $1 \mathrm{~mol} \%$ Cr(acac) $_{3}, 1$ phr $\mathrm{C}_{11} \mathrm{Z}, 1 \mathrm{phr}$ DICY, and $1 \mathrm{phr} \mathrm{BF}_{3} \mathrm{MEA}$ were represented as TGDDM/DDS/Cr(acac) 3 , TGDDM/ DDS/C ${ }_{11} Z$, TGDDM/DDS/DICY and TGDDM/DDS/ $\mathrm{BF}_{3} \mathrm{MEA}$, respectively. The mole percentage is based on moles of TGDDM resin in the systems assuming that TGDDM is the only ingredient in MY720. The phr is parts per hundred parts of TGDDM by weight. Those of TGDDM/DDS incorporating both $1 \mathrm{phr} \mathrm{C}_{11} \mathrm{Z}$ and $1 \mathrm{~mol} \% \mathrm{Cr}(\mathrm{acac})_{3}$, and both $1 \mathrm{phr}$ DICY and 1 mol\% $\mathrm{Cr}(\mathrm{acac})_{3}$ were represented as TGDDM/DDS/ $\mathrm{C}_{11} \mathrm{Z} / \mathrm{Cr}(\mathrm{acac})_{3}$ and TGDDM/DDS/DICY $/ \mathrm{Cr}(\mathrm{acac})_{3}$, respectively.

The ingredients were mixed at about $110^{\circ} \mathrm{C}$ until a clear solution was obtained. They were then degassed in a vacuum chamber pre-heated at $110^{\circ} \mathrm{C}$. To prepare the neat resin specimens, the mixtures were then poured into rectangular-shaped molds made from silicone rubber and cured for $2 \mathrm{~h}$ at $140^{\circ} \mathrm{C}$ plus $2 \mathrm{~h}$ at $177^{\circ} \mathrm{C}$ plus $4 \mathrm{~h}$ at $200^{\circ} \mathrm{C}$ for post cure. Cured specimens for moisture absorption tests and dynamic mechanical tests had dimensions of $30 \times 14 \times 2 \mathrm{~mm}$. After post curing, the specimens were stored in a desiccator at room temperature for at least 2 months prior to the initiation of experiments.

Prior to preparing the unidirectional sixteen-ply $\mathrm{Gr} / \mathrm{Ep}$ laminated specimens, a two-stage process was used for manufacturing the unidirectional Gr/Ep hotmelt-type prepregs: 1) coating the mixed epoxy formulations on a release paper; 2) impregnating the carbon

Table 1. Cure Schedules of Gr/Ep Laminates.

\footnotetext{
1. Pull $508 \mathrm{~mm}$ minimum vacuum on part.

2. Raise temperature to $120^{\circ} \mathrm{C}\left(\right.$ or $140^{\circ} \mathrm{C}$ ) at $2.5^{\circ} \mathrm{C} / \mathrm{min}$ for preheating.

3. Hold for $30 \mathrm{~min}$ at $120^{\circ} \mathrm{C}$ (or $140^{\circ} \mathrm{C}$ ) under vacuum only

4. Pressurize autoclave to $410 \mathrm{kPa}$.

5. Hold at $120^{\circ} \mathrm{C}$ (or $140^{\circ} \mathrm{C}$ ), $410 \mathrm{kPa}$, and vacuum on the part for $45 \mathrm{~min}$.

6. Raise temperature to $177^{\circ} \mathrm{C}$ at $2.5^{\circ} \mathrm{C} / \mathrm{min}$.

7. Hold for $2 \mathrm{~h}$.

8. Cool part to $60^{\circ} \mathrm{C}$ in not less than 100 min with pressure and vacuum maintained.

9. Remove from autoclave.
}

fibers with the coated release paper in a drum-type winding machine. The resin content and fiber areal weight of manufactured prepregs were controlled at $40 \pm 2 \mathrm{wt} \%$ and $137 \pm 1 \mathrm{~g} / \mathrm{m}^{2}$, respectively. Sixteenply unidirectional Gr/Ep laminated specimens were then fabricated in vacuum bags in an autoclave with one of the two cure schedules listed in Table 1, followed by post curing in an oven at $200^{\circ} \mathrm{C}$ for $4 \mathrm{~h}$. The difference between two cure schedules is only for preheating temperature: one was $120^{\circ} \mathrm{C}$ and the other was $140^{\circ} \mathrm{C}$. Unless specified, the pre-heating temperature to cure the laminates is regarded as $120^{\circ} \mathrm{C}$. The specimens after post curing were cooled to room temperature at $\sim 1^{\circ} \mathrm{C} / \mathrm{min}$. Samples for moisture absorption and dynamic mechanical tests were cut to $40 \times$ $15 \mathrm{~mm}$ by diamond saw. Sample edges were polished in order to remove the surface irregularities. After that, the samples were stored in a desiccator at room temperature for at least two months prior to the initiation of experiments.

\section{Testing}

The viscosity of epoxy formulations used to prepare the Gr/Ep prepregs was measured by rheometer (Rheometrics Co., RMS-605 model) by the temperature schedule used in the autoclave. The resin content of the cured laminates was measured according to Ref. 12. The distribution of fibers in the cross section of cured laminates was observed by optical microscopy (Nikon Optical Microscope, Optiphot $100 \mathrm{~S}$ model), whereas the distribution of DDS curing agent in between two carbon fibers was investigated by line scanning of sulfur content using an electron probe microanalyzer (EPMA, JEOL JXA-821MX model).

Prior to the moisture absorption experiments, samples were dried to a constant weight in a desiccator at $60^{\circ} \mathrm{C}$ and $70^{\circ} \mathrm{C}$, respectively. Absorptions for pre-dried samples at $60^{\circ} \mathrm{C}$ were conducted in an environmental chamber at $60^{\circ} \mathrm{C} / 100 \% \mathrm{RH}$ and for those pre-dried at $70^{\circ} \mathrm{C}$ were conducted at $70^{\circ} \mathrm{C} / 100 \% \mathrm{RH}$. Infrared (IR) spectra of the neat resin samples were recorded on a Jasco 300E Fourier-transform IR spectrometer with $\mathrm{KBr}$ pellets. To eliminate the moisture interference, the tests were conducted at $110^{\circ} \mathrm{C}$. Dynamic mechanical analysis (DMA) of dry and moist samples were preformed in a DuPont 9900-983 dynamic mechanical analyzer. Tests were run at a heating rate of $10^{\circ} \mathrm{C} /$ min and at an oscillation amplitude of $0.2 \mathrm{~mm}$ peak to peak for neat resin and $0.1 \mathrm{~mm}$ for $\mathrm{Gr} / \mathrm{Ep}$ laminates. To hinder the escape of absorbed moisture from the samples, the specimens were sealed with aluminum foil.

\section{RESULTS AND DISCUSSION}

Figure 1 shows the moisture gains of the unidirectional $\mathrm{Gr} / \mathrm{Ep}$ laminates prepared with various epoxy formulations as a function of exposure time at $60^{\circ} \mathrm{C} /$ $100 \% \mathrm{RH}$ environment. Their resin content and maximum (or saturated) moisture absorption are listed in 


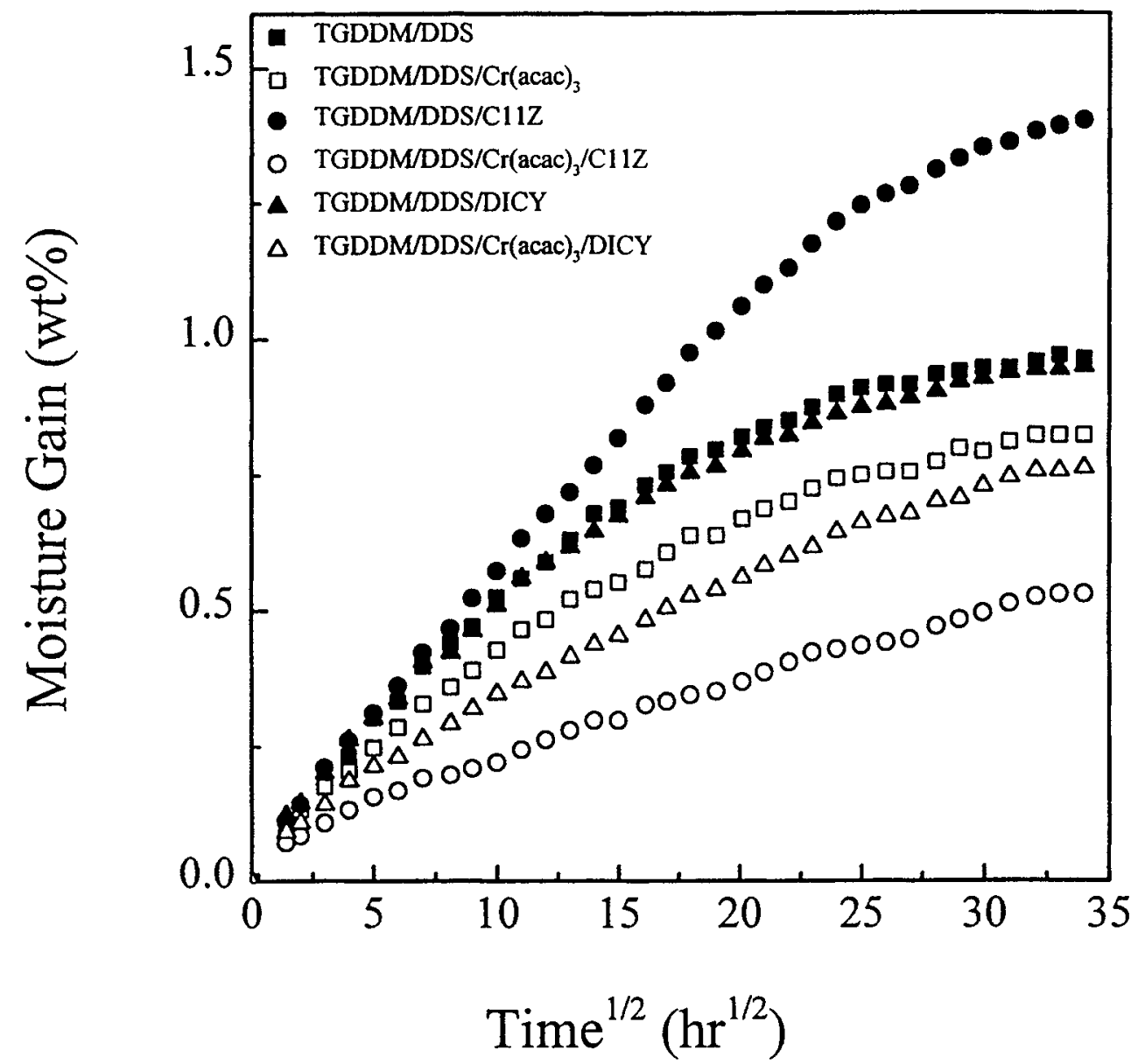

Fig. 1. Moisture gain of various unidirectional $\mathrm{Gr} / \mathrm{Ep}$ laminates at $60^{\circ} \mathrm{C} / 100 \% R \mathrm{H}$ as a function of square root of time.

Table 2. Apparently, the laminates containing $\mathrm{Cr}$ (acac) $)_{3}$ had a lower moisture absorption than those without. In addition, the laminate prepared by TGDDM/DDS/ $\mathrm{C}_{11} \mathrm{Z}$ had the highest moisture absorption and resin content, whereas that prepared by TGDDM/DDS/ $\mathrm{C}_{11} \mathrm{Z} / \mathrm{Cr}(\mathrm{acac})_{3}$ had the lowest moisture absorption but its resin content is rather high compared to other formulations. If the resin matrix was the only place to absorb the moisture, the saturated moisture content of TGDDM/DDS epoxy matrix would be the highest as indicated in Table 2.
Assuming that the moisture absorption of laminates followed the Fickian second law, the apparent diffusivity, $D$, of laminates could be estimated from the initial linear portion of the curves in Fig. 1 by using the following equation (13),

$$
D=\pi\left(\frac{h}{4 M_{m}}\right)^{2}\left(\frac{M_{2}-M_{1}}{\sqrt{t_{2}}-\sqrt{t_{1}}}\right)^{2}
$$

Where $M_{1}$ and $M_{2}$ are the weight percentage of moisture absorbed at $t_{1}$ and $t_{2}$ respectively, $M_{m}$ is the

Table 2. Moisture Absorption Data of Various Gr/Ep Laminates at $60^{\circ} \mathrm{C} / 100 \% \mathrm{RH}$.

\begin{tabular}{|c|c|c|c|c|c|c|c|}
\hline Epoxy Formulations & $\underset{(w t \%)}{M_{m}^{a}}$ & $\begin{array}{c}\text { Resin Content } \\
(w t \%)\end{array}$ & $\begin{array}{c}M_{m}^{b} \\
(w t \%)\end{array}$ & D & $D_{r}$ & (h) & $\mathbf{D}_{22}$ \\
\hline $\begin{array}{l}\text { TGDDM/DDS } \\
\text { TGDDM/DDS/ } \\
\text { Cr(acac })_{3}\end{array}$ & $\begin{array}{l}0.969 \\
0.823\end{array}$ & $\begin{array}{l}21 \\
22\end{array}$ & $\begin{array}{l}4.61 \\
3.74\end{array}$ & $\begin{array}{l}2.65 \\
2.75\end{array}$ & $\begin{array}{l}43.2 \\
38.4\end{array}$ & $\begin{array}{l}11.3 \\
10.6\end{array}$ & $\begin{array}{l}1.34 \\
1.51\end{array}$ \\
\hline $\begin{array}{l}\text { TGDDM/DDS/C } \mathrm{C}_{11} \mathrm{Z} \\
\mathrm{TGDDM} \mathrm{DDS} / \\
\mathrm{C}_{11} \mathrm{Z} / \mathrm{Cr}(\mathrm{acac})_{3}\end{array}$ & $\begin{array}{l}1.402 \\
0.530\end{array}$ & $\begin{array}{l}33 \\
27\end{array}$ & $\begin{array}{l}4.25 \\
1.96\end{array}$ & $\begin{array}{l}3.01 \\
1.99\end{array}$ & $\begin{array}{l}12.3 \\
14.7\end{array}$ & $\begin{array}{l}5.08 \\
5.48\end{array}$ & $\begin{array}{l}1.66 \\
1.20\end{array}$ \\
\hline $\begin{array}{l}\text { TGDDM/DDS/DICY } \\
\text { TGDDM/DDS/ } \\
\text { DICY/Cr(acac) })_{3}\end{array}$ & $\begin{array}{l}0.948 \\
0.762\end{array}$ & $\begin{array}{l}24 \\
25\end{array}$ & $\begin{array}{l}3.95 \\
3.05\end{array}$ & $\begin{array}{l}3.13 \\
2.61\end{array}$ & $\begin{array}{l}30.5 \\
23.1\end{array}$ & $\begin{array}{l}9.16 \\
7.21\end{array}$ & $\begin{array}{l}1.71 \\
1.49\end{array}$ \\
\hline
\end{tabular}

The moisture gain by laminates after $1200 \mathrm{~h}$.

The moisture gain by resin matrix after $1200 \mathrm{~h}$, assuming only resin matrix absorbed moisture 

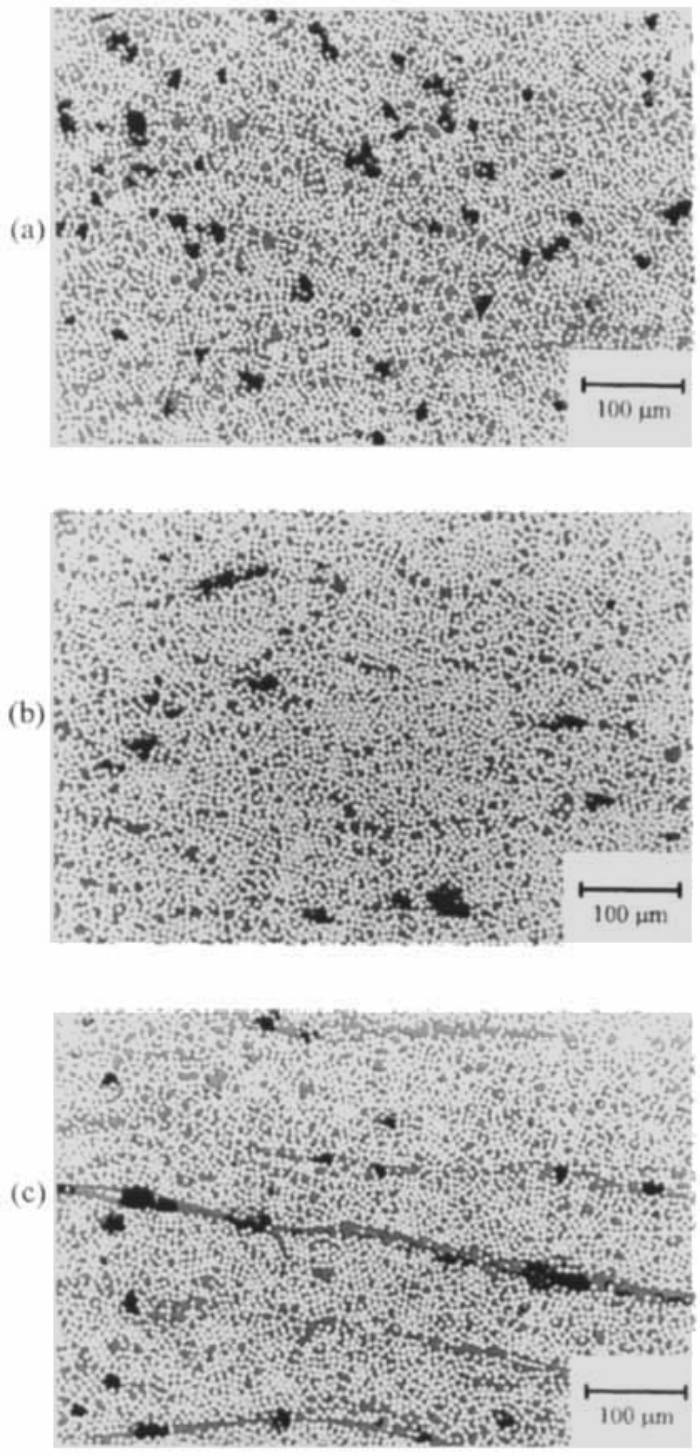
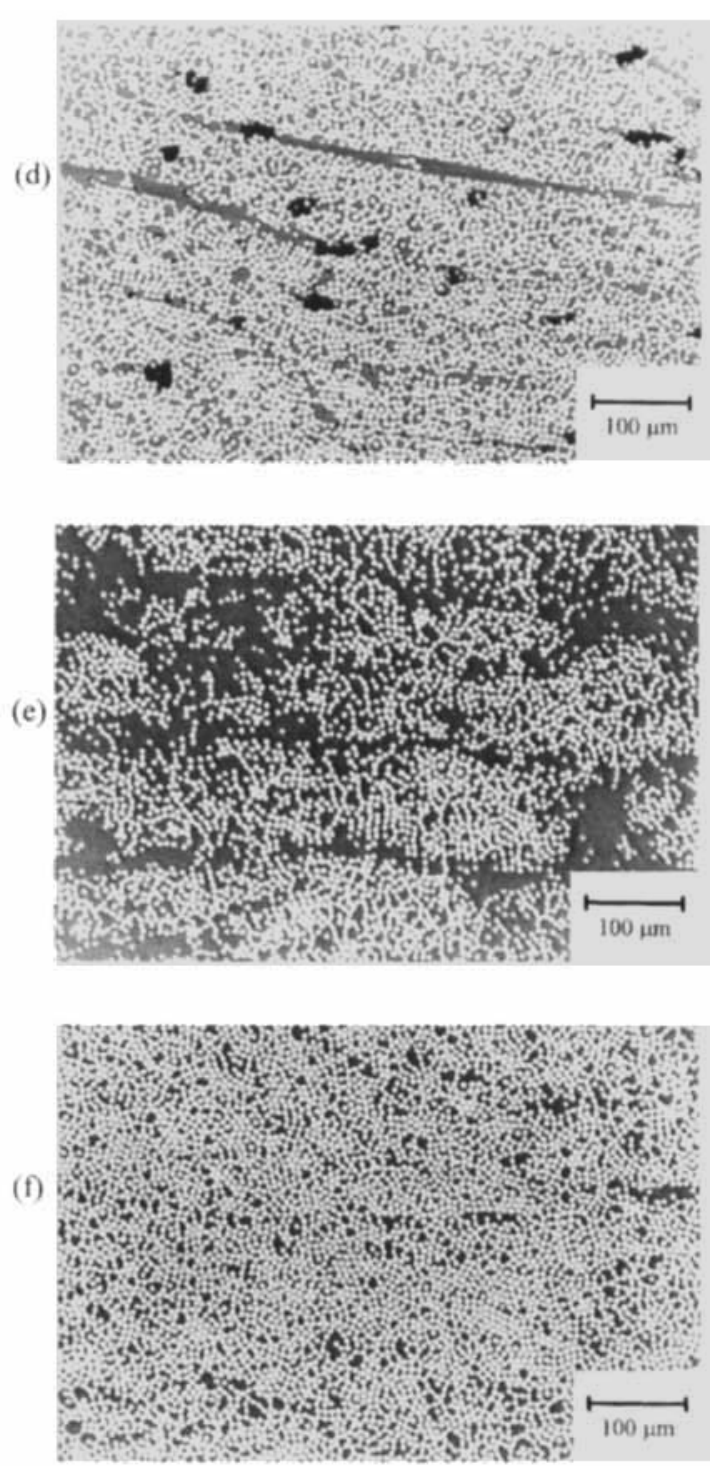

Fig. 2. Photomicrographs of the cross section of unidirectional Gr/Ep laminates prepared by various epoxy formulations; (a) TGDDM/DDS, (b) TGDDM/DDS/Cr(acac) 3 , (c) TGDDM/DDS/DICY, (d) TGDDM/DDS/DICY/Cr(acac) ${ }_{3}$, (e) TGDDM/DDS/C ${ }_{11} Z$, and (f) $T G D D M / D D S / C_{11} Z / C r(a c a c)_{3}$.

weight percentage of absorbed moisture at saturation, and $h$ is the thickness of the specimens. Due to the fact that the carbon fiber does not absorb the moisture, the apparent diffusivity could also be used to calculate the diffusivity of resin matrix, $D_{r}$, by using the following equation (13),

$$
\begin{aligned}
& D=D_{\mathrm{r}}\left(1-2 \sqrt{v_{f} / \pi}\right) \\
& {\left[1+\frac{h}{l}+\frac{h}{n} \sqrt{\frac{\left(1-v_{f}\right)}{\left(1-2 \sqrt{\left.v_{f} / \pi\right)}\right.}}\right]^{2} }
\end{aligned}
$$

Where $v_{f}$ is the volume fraction of carbon fibers; 1 and $n$ are the length and width of the specimens. Then, the diffusivities in the fiber direction of the specimens, $D_{11}$, and in the transverse direction, $D_{22}$, could be calculated by

$$
\begin{gathered}
D_{11}=\left(1-v_{f}\right) D_{r} \\
D_{22}=\left(1-2 \sqrt{v_{f} / \pi}\right) D_{r}
\end{gathered}
$$

The calculated $D_{r} D_{11}$, and $D_{22}$ of the laminated samples are all included in Table 2.

Figure 2 shows the photomicrographs of the cross section of unidirectional Gr/Ep laminates prepared by various epoxy formulations. In general, the voids were found in the laminates with the resin content less than $27 \mathrm{wt} \%$ and the void content increased with decreasing the resin content. No void was found for the laminates prepared by TGDDM/DDS $/ \mathrm{C}_{11} Z$ and TGDDM/DDS $/ \mathrm{C}_{11} Z / \mathrm{Cr}$ (acac) $)_{3}$. Apparently, $\mathrm{C}_{11} Z$ was an effective curing accelerator to increase the resin content of laminates. 


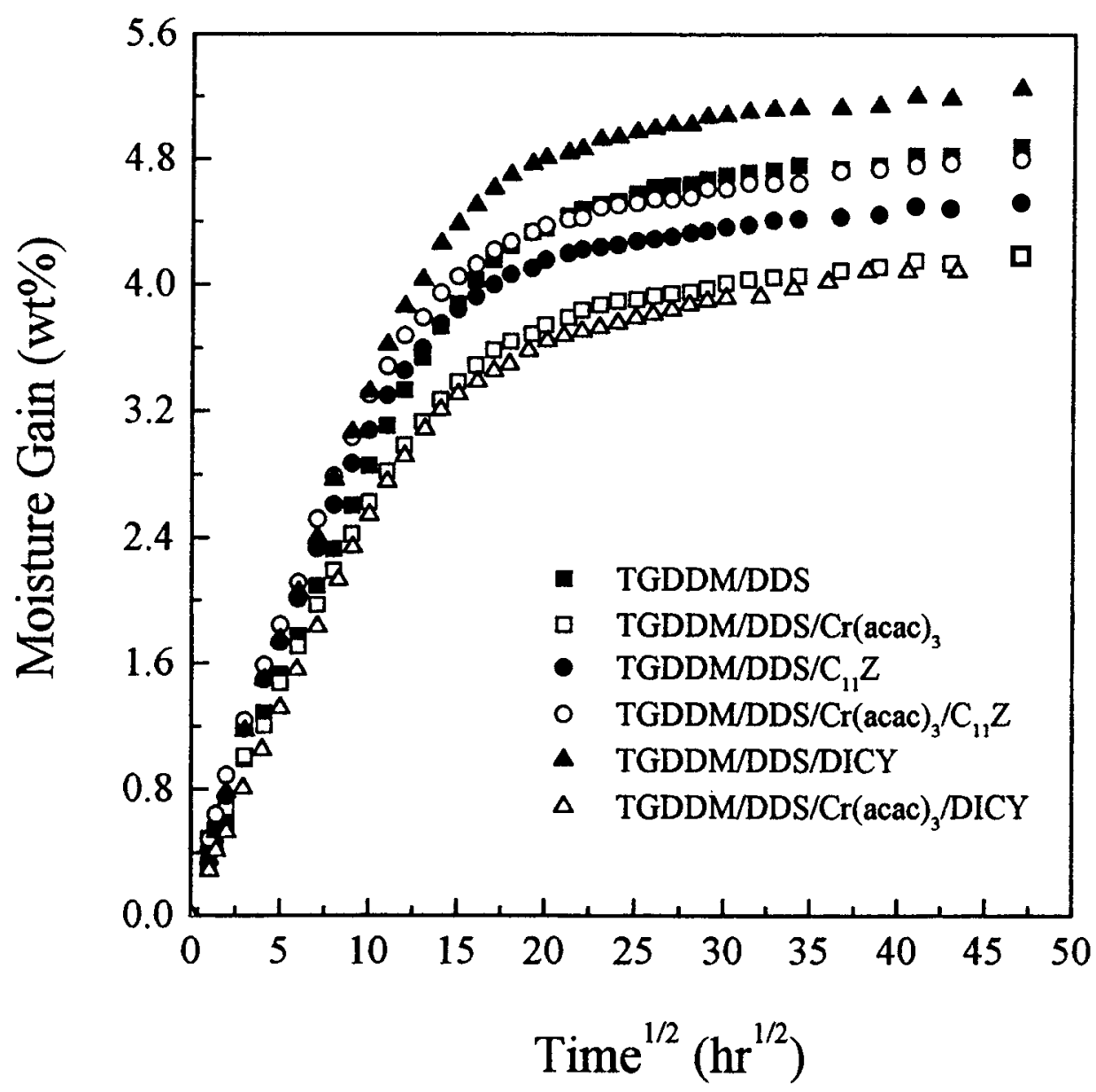

Fig. 3. Moisture gain of various epoxy resins at $60^{\circ} \mathrm{C} / 100 \% \mathrm{RH}$ as a function of square root of time.

Figure 3 shows the moisture gain of neat resins prepared by the same resin formulations as the laminates and also exposed to the same moist environment of $60^{\circ} \mathrm{C} / 100 \% \mathrm{RH}$. Their maximum (or saturated) moisture contents and calculated apparent diffusivity, $D_{n}$, from $E q 1$ were listed in Table 3. Interestingly, the incorporation of $\mathrm{Cr}(\mathrm{acac})_{3}$ decreased the moisture absorption for TGDDM/DDS and TGDDM/DDS/DICY epoxy formulations but not for TGDDM/DDS $/ C_{11} Z$. Since it has been indicated that the incorporation of Cr(acac) $)_{3}$ was able to block the hydroxyl groups of epoxy resins, the content of hydroxyl groups of cured samples from different epoxy formulations were estimated by using FTIR technique. To eliminate the in- terference of moisture, the tests were conducted at $110^{\circ} \mathrm{C}$. The data were taken after the intensity of hydroxyl peak at $3500 \mathrm{~cm}^{-1}$ was stabilized. They were listed in Table 3 by using a phenyl peak at $815 \mathrm{~cm}^{-1}$ as a reference. Thus, the efficiency to decrease the hydroxyl groups of epoxy resins by incorporating Cr(acac) ${ }_{3}$ could be compared. The efficiency was the highest for TGDDM/DDS/DICY and the lowest for TGDDM/DDS/ $\mathrm{C}_{11} Z$. The results could be used to explain that the incorporation of $\mathrm{Cr}(\mathrm{acac})_{3}$ to decrease the moisture absorption of TGDDM/DDS/DICY resins had higher efficiency than to decrease that of TGDDM/DDS. However, the incorporation of $\mathrm{Cr}$ (acac) 3 into TGDDM/DDS $/ \mathrm{C}_{11} \mathrm{Z}$ resins increased the mois-

Table 3. Moisture Absorption Data of Various Epoxy Resins at $60^{\circ} \mathrm{C} / 100 \% \mathrm{RH}$.

\begin{tabular}{|c|c|c|c|}
\hline Resin Formulations & $\underset{(w t \%)}{M_{m}}$ & $\begin{array}{c}D_{n} \\
\left(\times 10^{3} \mathrm{~mm} / \mathrm{h}\right)\end{array}$ & $\begin{array}{c}{[\mathrm{OH}]^{\mathrm{a}}} \\
\left(\mathrm{I}_{\left.3500 \mathrm{~cm}^{-1} \Lambda_{850 \mathrm{~cm}^{-1}}\right)}\right)\end{array}$ \\
\hline $\begin{array}{l}\text { TGDDM/DDS } \\
\text { TGDDM/DDS/Cr(acac })_{3} \\
\text { TGDDM/DDS/C }_{11} Z \\
\text { TGDDM/DDS/C }_{11} \mathrm{Z} / \mathrm{Cr}(\mathrm{acac})_{3} \\
\text { TGDDM/DDS/DICY } \\
\text { TGDDM/DDS/DICY/Cr(acac) })_{3}\end{array}$ & $\begin{array}{l}4.82 \\
4.15 \\
4.50 \\
4.76 \\
5.20 \\
4.09\end{array}$ & $\begin{array}{l}3.42 \\
4.39 \\
4.03 \\
3.76 \\
3.62 \\
3.18\end{array}$ & $\begin{array}{l}1.74 \\
1.22 \\
1.21 \\
0.89 \\
1.25 \\
0.78\end{array}$ \\
\hline
\end{tabular}

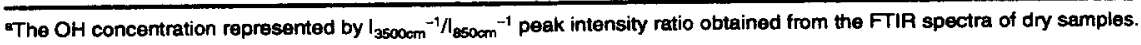




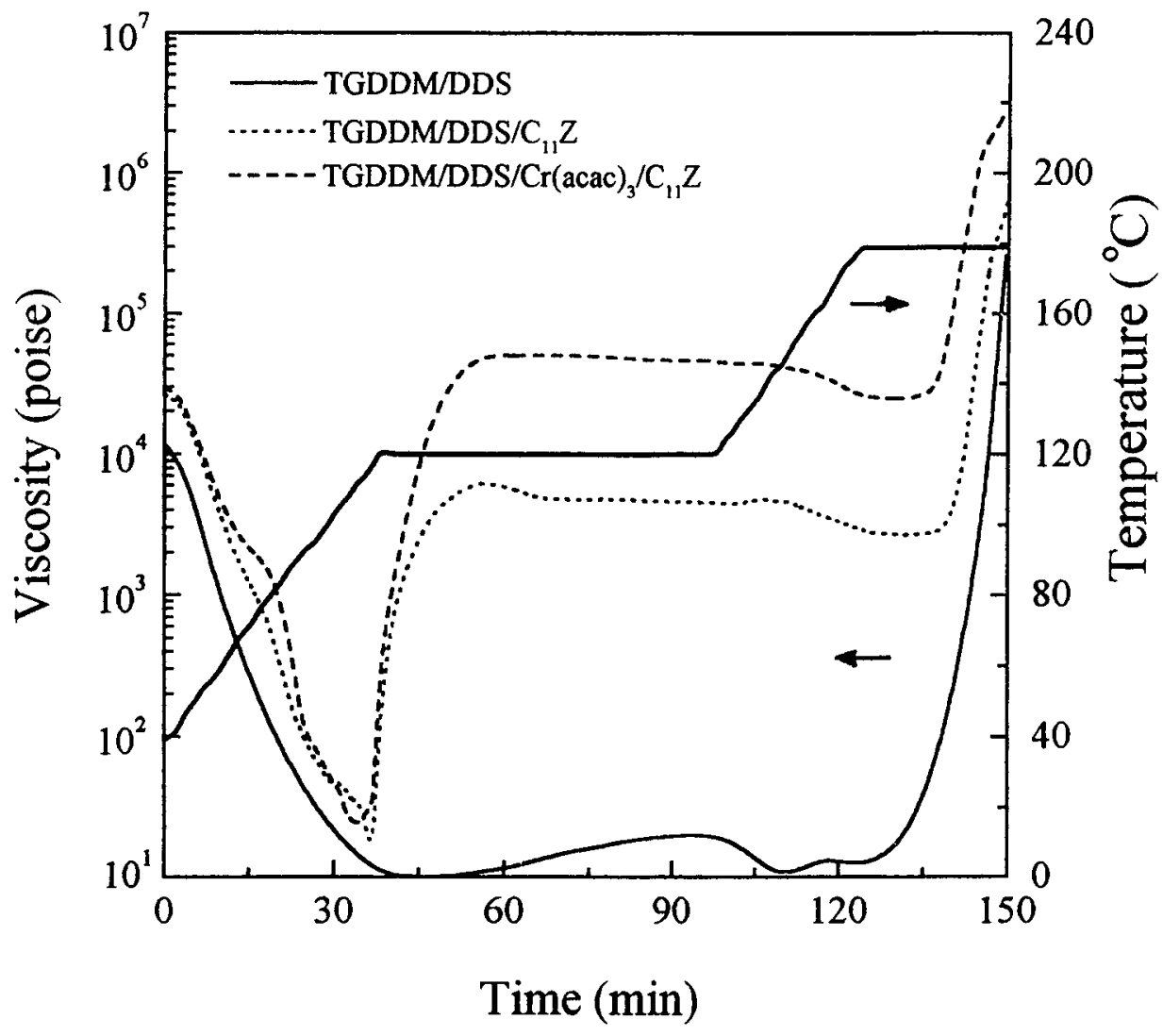

Fig. 4. The viscosity of various epoxy matrices as functions of curing time and the indicated temperature schedule used to prepare the $\mathrm{Gr} / \mathrm{Ep}$ laminates (for $120^{\circ} \mathrm{C}$ preheating temperature process).

ture absorption as indicated in Fig. 3. The unexpected results might be because the $C_{11} Z$ reacted with TGDDM first. The generated ether-linkage polymer chains diluted the concentration of hydroxyl groups yielded by the following reactions of TGDDM/DDS. Thus, the incorporation of $\mathrm{Cr}(\mathrm{acac})_{3}$ might not fully interact with the diluted hydroxyl groups and had a chance to absorb more moisture.

Since the incorporation of $\mathrm{Cr}(\mathrm{acac})_{3}$ into TGDDM/ $\mathrm{DDS} / \mathrm{C}_{11} Z$ neat resin did not decrease the moisture absorption, the decrease of moisture absorption for their prepared $\mathrm{Gr} / \mathrm{Ep}$ laminates might be associated with the processing condition of laminates. Figure 4 shows the viscosity of the epoxy matrices of TGDDM/DDS, TGDDM/DDS/ $\mathrm{C}_{11} Z$, and TGDDM/ $\mathrm{DDS} / \mathrm{C}_{11} \mathrm{Z} / \mathrm{Cr}$ (acac) $)_{3}$ respectively, as functions of curing time and the temperature schedule used to prepare the laminates. The viscosities decreased at almost the same rate for three epoxy formulations in the initial heating stage from 40 to $120^{\circ} \mathrm{C}$. When the temperature reached $120^{\circ} \mathrm{C}$, the viscosity of TGDDM/DDS $/ C_{11} Z$ rapidly increased to 4,000 poise and began to deviate from that of the TGDDM/DDS. The increased viscosity was due to the curing reactions of TGDDM and $C_{11} Z$ (9). Once the reaction stopped, the viscosity stayed at that level. On the other hand, the viscosity of TGDDM/DDS $/ \mathrm{C}_{11} \mathrm{Z} / \mathrm{Cr}(\text { acac })_{3}$ increased even higher, which was attributed to the interactions of $\mathrm{Cr}(\mathrm{acac})_{3}$ with the small amount of hydroxyl groups in the reacted TGDDM $/ \mathrm{C}_{11} \mathrm{Z}$ molecules (9).

Because the prepregs were manufactured by the hot-melt process, the impregnation of carbon fibers in the prepregs was never completed. In the lamination stage, the applied high pressure after the reactions of TGDDM with $\mathrm{C}_{11} \mathrm{Z}$ at $120^{\circ} \mathrm{C}$ might squeeze the small molecules such as unreacted TGDDM, DDS, and $\mathrm{Cr}(\mathrm{acac})_{3}$ toward the surface of carbon fibers. It was believed to result in the inhomogeneous dispersion of TGDDM/DDS/Cr(acac) 3 curing networks in the epoxy matrix, especially in between the bulk regions and the interphase regions of reinforcing carbon fibers. Since only DDS contains sulfur element in the molecular structure, we have employed the EPMA surface analyzer to investigate the concentration of sulfur in between two carbon fibers by line scanning the cross section of laminates prepared by TGDDM/DDS/ $\mathrm{C}_{11} \mathrm{Z} / \mathrm{Cr}(\mathrm{acac})_{3}$ and TGDDM/DDS $/ \mathrm{Cr}(\mathrm{acac})_{3}$, respectively. Typical results were shown in Fig. 5, which indicated that the inhomogeneous dispersion of DDS in between carbon fibers for the laminates prepared by TGDDM/DDS/ $\mathrm{C}_{11} \mathrm{Z} / \mathrm{Cr}$ (acac) $_{3}$ epoxy formulation was much greater than those prepared by TGDDM/DDS/ Cr(acac) ${ }_{3}$. Apparently, the pre-reaction of TGDDM/C $\mathrm{C}_{11} \mathrm{Z}$ 
Fig. 5. Typical line-scanning sulfur concentration distributions by EPMA on the cross-section of unidirectional $\mathrm{Gr} / \mathrm{Ep}$ laminates prepared from (a) TGDDM/DDS/C ${ }_{11} Z /$ $\mathrm{Cr}(\mathrm{acac})_{3}$ and (b) TGDDM/DDS/ $\mathrm{Cr}(\mathrm{acac})_{3}$.

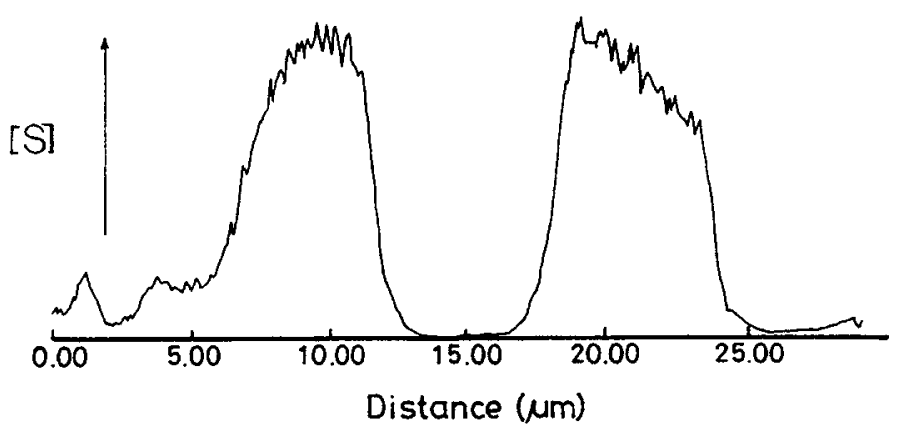

(b)

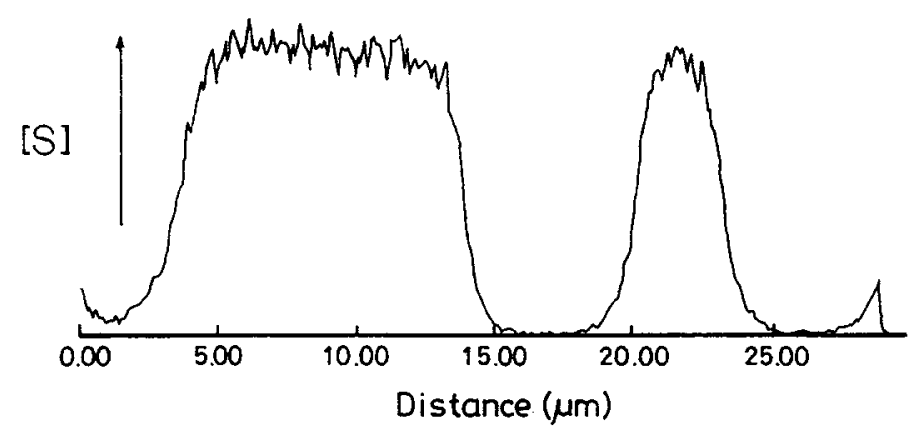

has caused the inhomogeneous dispersion of DDS in between the interphase region and bulk region of the epoxy matrix.

Since the viscosity of TGDDM/DDS/C $\mathrm{C}_{11} \mathrm{Z} / \mathrm{Cr}$ (acac) 3 formulation was higher than that of TGDDM/DDS/ $\mathrm{C}_{11} Z$ during pressurizing stage, more inhomogeneous dispersion of DDS was expected. The $T_{g}$ peak in the loss modulus spectrum of the laminate prepared by TGDDM/DDS $/ \mathrm{C}_{11} \mathrm{Z} / \mathrm{Cr}(\mathrm{acac})_{3}$ was broader compared to that prepared by the TGDDM/DDS/C $\mathrm{C}_{11} \mathrm{Z}$ formulation as shown in Fig. 6. Its storage modulus spectrum at $T_{g}$ also shows a two-step descent, indicating that two crosslinking networks i.e., a TGDDM $/ C_{11} Z$-richer

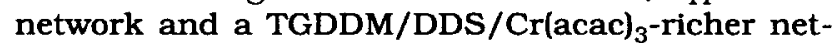
work were formed in the epoxy matrix. Because the TGDDM $/ \mathrm{C}_{11} Z$-richer network has more ether linkages than the TGDDM/DDS/Cr(acac) ${ }_{3}$-richer network, its $T_{g}$ should be lower.

Both TGDDM/C 11 -richer and TGDDM/DDS/ $\mathrm{Cr}$ (acac) $)_{3}$-richer networks are low moisture absorptive networks in the laminates. Once the two epoxy networks separated in the laminate, they would not interfere with each other as they did in the neat resin. Thus, the addition of both $\mathrm{Cr}(\text { acac })_{3}$ and $\mathrm{C}_{11} \mathrm{Z}$ to the TGDDM/DDS epoxy formulation had the synergistic effect of reducing the moisture absorption of the prepared laminates but not for the neat resins. After saturation with moisture, the $T_{g}$ of laminates prepared by TGDDM/DDS $/ \mathrm{C}_{11} \mathrm{Z} / \mathrm{Cr}$ (acac) $_{3}$ only decreased by $34.4^{\circ} \mathrm{C}$ whereas that of laminates prepared by TGDDM/DDS $/ \mathrm{C}_{11} \mathrm{Z}$ decreased by $52.6^{\circ} \mathrm{C}$.

To provide further evidence to support our explanation, we increased the pre-heating temperature to $140^{\circ} \mathrm{C}$ in the lamination stage in order to lower the viscosity while pressuring the laminates. The viscosity of epoxy matrix as a function of curing time at the temperature schedule used to cure the laminates with $140^{\circ} \mathrm{C}$ pre-heating temperature has been published in the other study (9), which hereby we quote in Fig. 7. The viscosity of TGDDM/DDS/C 11 Z/Cr(acac) ${ }_{3}$ epoxy matrix preheating at $140^{\circ} \mathrm{C}$ was only one fifth that of the same epoxy matrix pre-heating at $120^{\circ} \mathrm{C}$, presumably resulting in a less inhomogeneous epoxy network after cure. When the laminates cured with two different temperature schedules were subjected to moisture absorption at $70^{\circ} \mathrm{C} / 100 \% \mathrm{RH}$ environment, those with $140^{\circ} \mathrm{C}$ pre-heating temperature showed less difference in moisture gain between the TGDDM/DDS/C $\mathrm{C}_{11} Z$ and TGDDM/DDS $/ \mathrm{C}_{11} Z / \mathrm{Cr}$ (acac) ${ }_{3}$ epoxy matrixes as shown in Fig. 8. On the other hand, the moisture absorption of laminates prepared of TGDDM/DDS/ $\mathrm{Cr}$ (acac) $)_{3}$ was not much affected by the pre-heating temperature during lamination. For comparison, the moisture absorption of the laminate prepared by TGDDM/DDS/BF 3 MEA was included in Fig. 8, since its resin formulation is frequently used to prepare 
Low Moisture Absorptive Epaxy Formulations for Gr/Ep Laminates

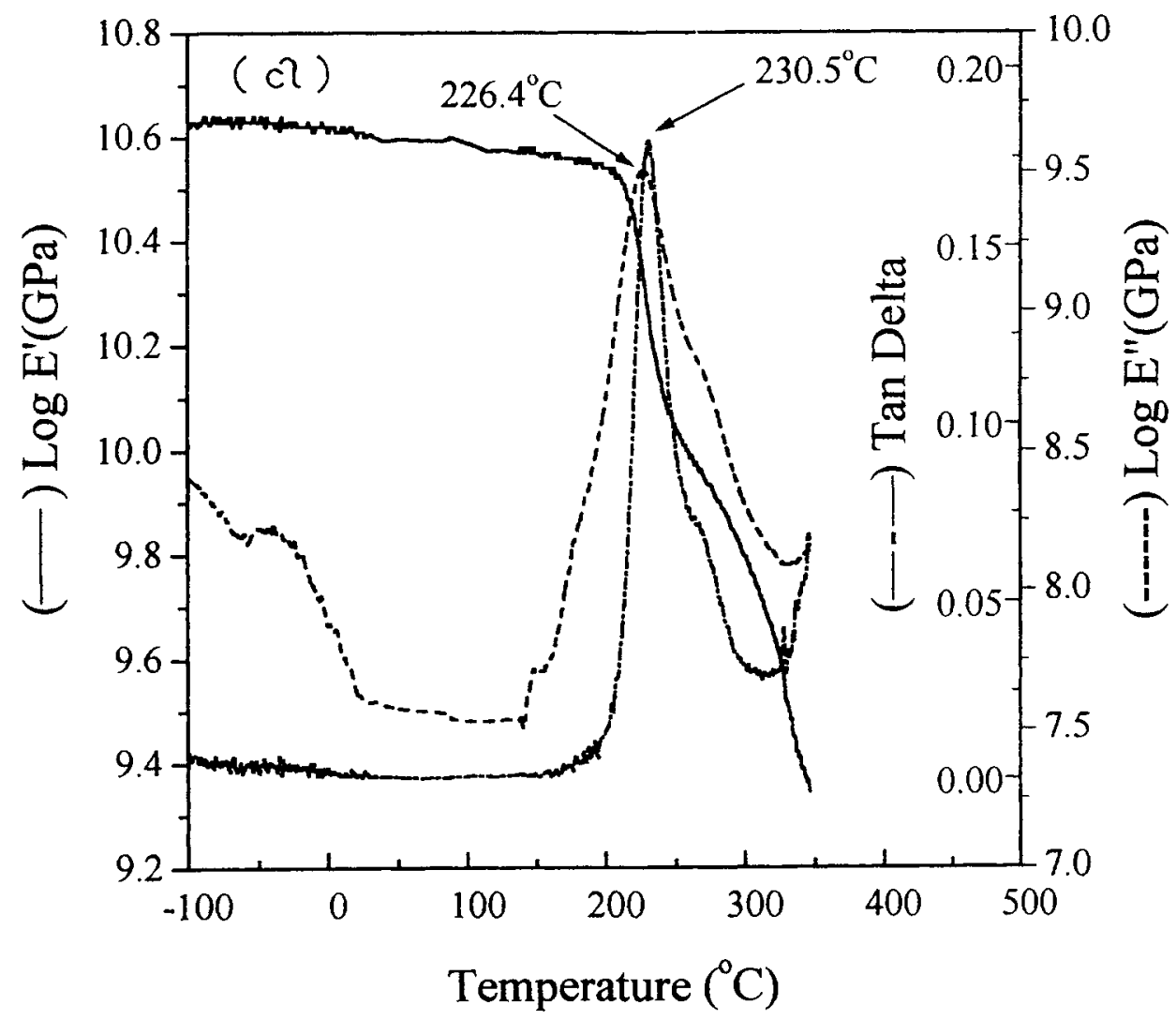

Fig. 6. DMA spectra of unidirectional $\mathrm{Gr} / \mathrm{Ep}$ laminates prepared from (a) TGDDM/DDS/C $C_{11} Z /$ $\mathrm{Cr}(\mathrm{acac})_{3}$ and (b) TGDDM/DDS/ $C_{11}$.

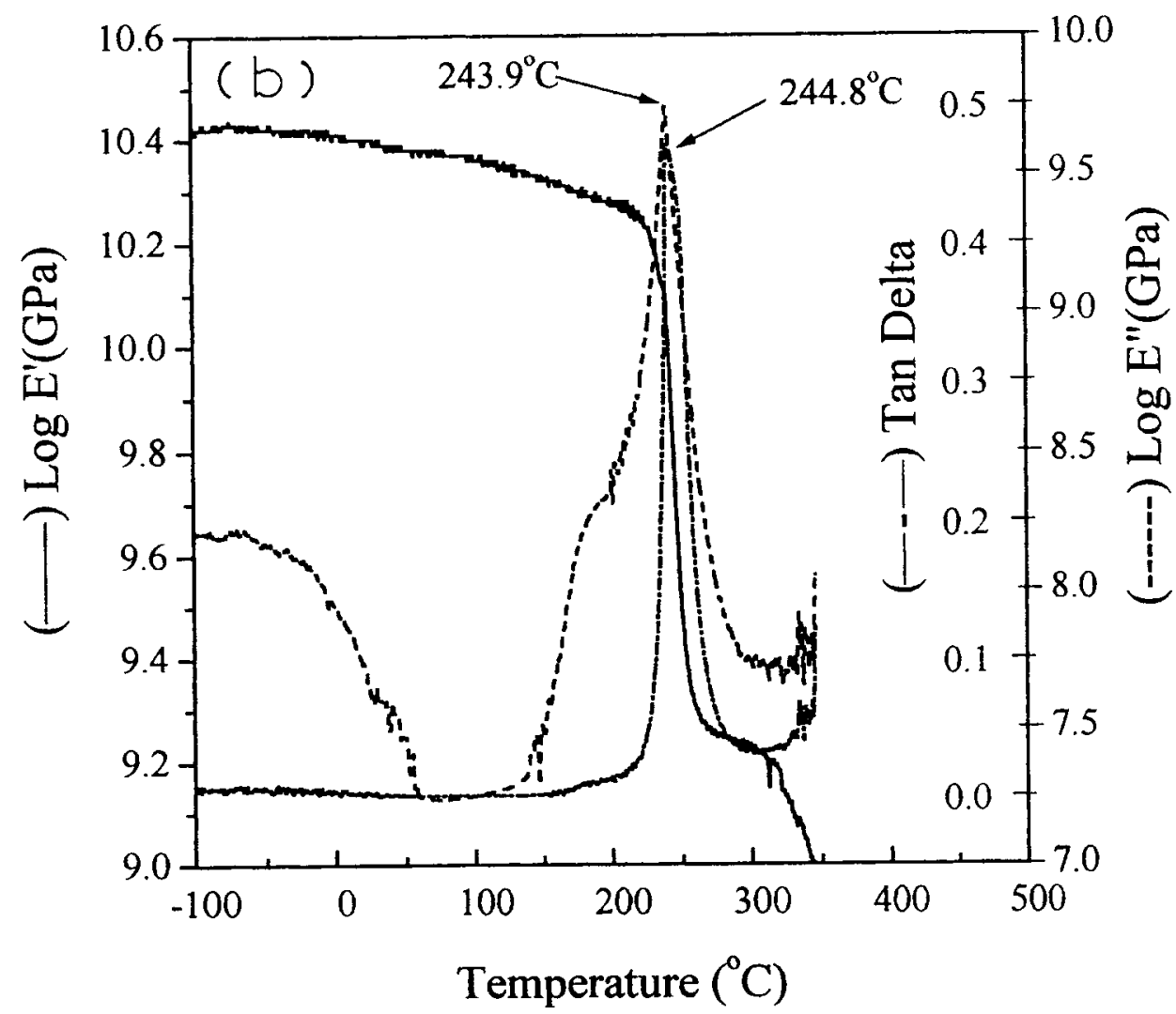

(b) 


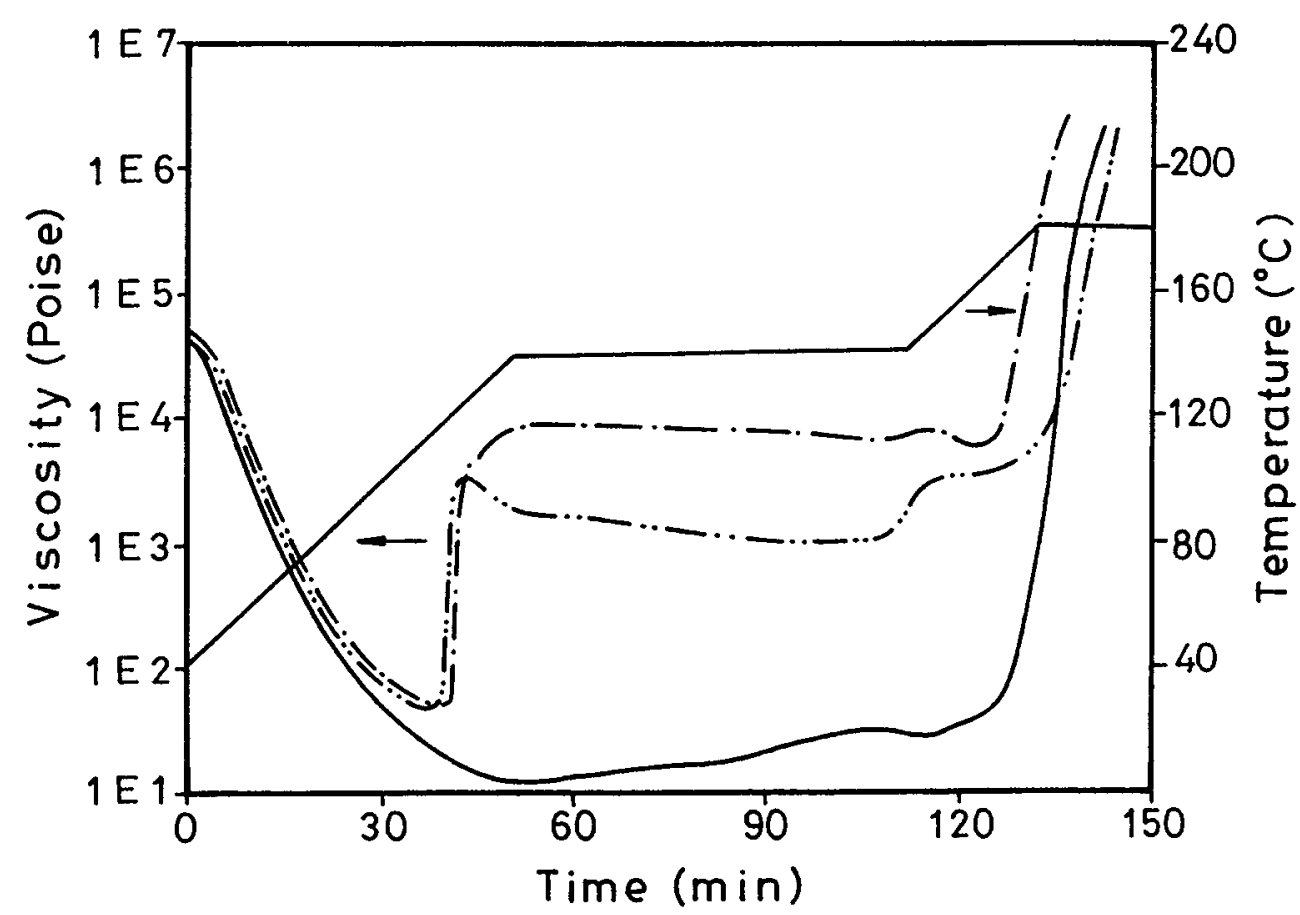

Fig. 7. The viscosity of various epoxy matrices as functions of curing time and the indicated temperature schedule used to prepare the $\mathrm{Gr} / \mathrm{Ep}$ laminates (for $140^{\circ} \mathrm{C}$ preheating temperature process): ( $\rightarrow$ TGDDM/DDS, (-..-) TGDDM/DDS/C $\mathrm{T}_{11} Z$, and (- - ) TGDDM/ $\left.D D S / C_{11} Z / C_{(a c a c}\right)_{3}(9)$.

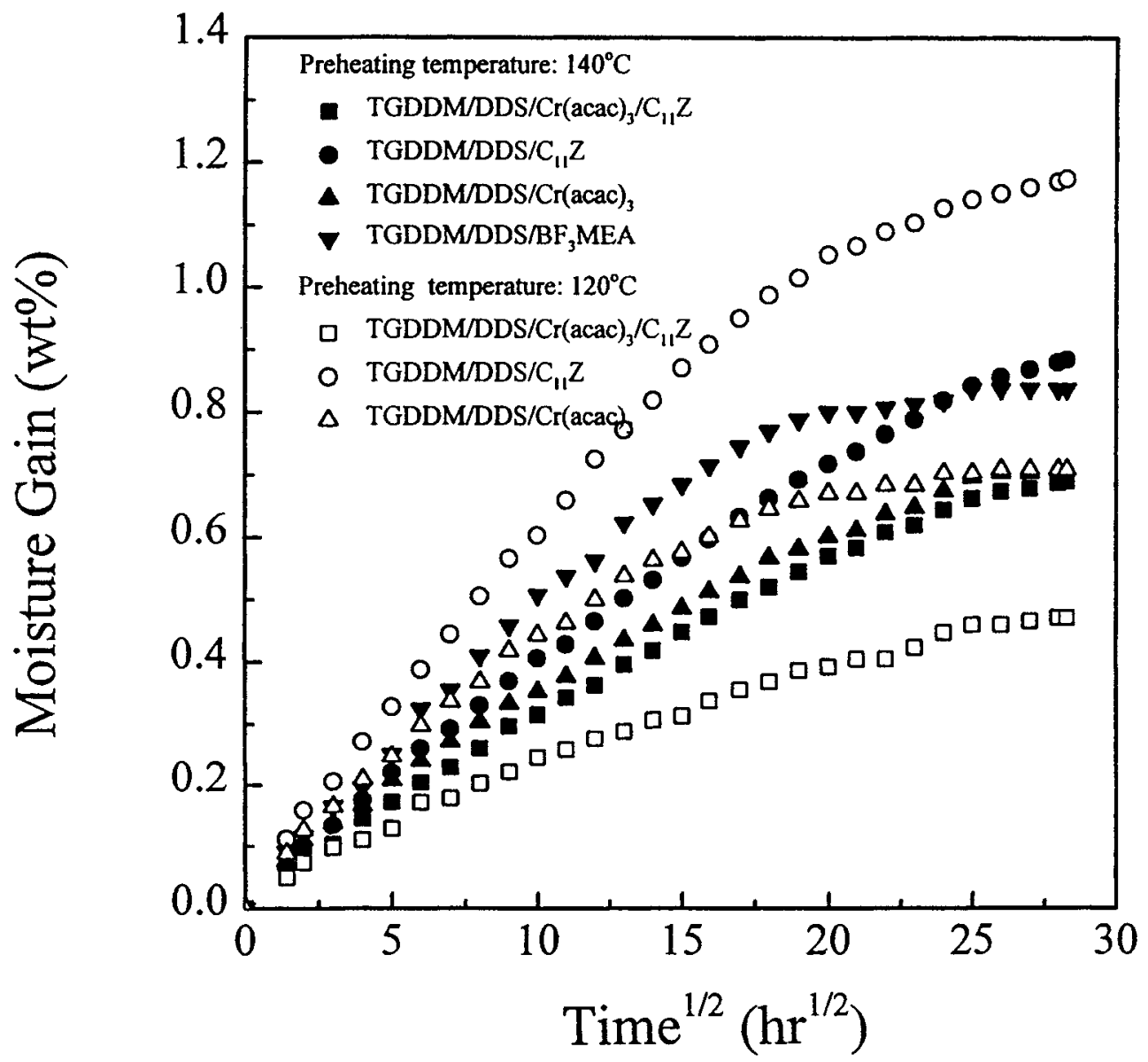

Fig. 8. Moisture gain of various unidirectional $\mathrm{Gr} / \mathrm{Ep}$ laminates at $70^{\circ} \mathrm{C} / 100 \% \mathrm{RH}$ as a function of square root of time. 
Table 4. Moisture Absorption Data of Various Gr/Ep Laminates at $70^{\circ} \mathrm{C} / 100 \% \mathrm{RH}$.

\begin{tabular}{|c|c|c|c|c|c|}
\hline $\begin{array}{l}\text { Preheating Temp." } \\
\qquad\left({ }^{\circ} \mathrm{C}\right)\end{array}$ & Epoxy Formulations & $\begin{array}{c}\text { Resin Content } \\
(w t \%)\end{array}$ & $\begin{array}{c}M_{m}^{b} \\
(w t \%)\end{array}$ & $\underset{(w t \%)}{M_{m}^{c}}$ & $\underset{\left(m^{2} / h\right)}{D}$ \\
\hline 120 & 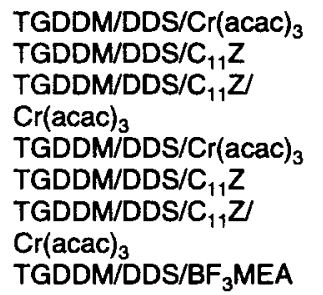 & $\begin{array}{l}22 \\
33 \\
27 \\
\\
24 \\
30 \\
30 \\
\\
27\end{array}$ & $\begin{array}{l}0.709 \\
1.175 \\
0.471 \\
\\
0.708 \\
0.884 \\
0.689 \\
\\
0.836\end{array}$ & $\begin{array}{l}3.22 \\
3.56 \\
1.746 \\
\\
2.94 \\
2.95 \\
2.30 \\
\\
3.10\end{array}$ & $\begin{array}{l}3.12 \times 10^{-3} \\
3.80 \times 10^{-3} \\
2.38 \times 10^{-3} \\
\\
6.33 \times 10^{-3} \\
7.21 \times 10^{-3} \\
5.52 \times 10^{-3} \\
2.75 \times 10^{-3}\end{array}$ \\
\hline
\end{tabular}

Preheating temperature during lamination as indicated in Table 1.

The moisture gain by laminates atter $800 \mathrm{~h}$.

The moisture gain by resin matrix aher $800 \mathrm{~h}$, assuming only resin matrix absorbed moisture.

commercial laminates. The resin content and maximum moisture absorptions of laminates and their resin matrices (assuming only resin matrix absorbed moisture) are listed in Table 4 . The fact that the high pre-heating temperature decreased the moisture absorption of TGDDM/DDS/ $\mathrm{C}_{11} \mathrm{Z}$ epoxy matrix might result from the higher extent of curing reactions between TGDDM and $\mathrm{C}_{11} \mathrm{Z}$. The increase of moisture absorption of the TGDDM/DDS/ $\mathrm{C}_{11} \mathrm{Z} / \mathrm{Cr}\left(\right.$ acac $_{3}$ epoxy matrix with increased pre-heating temperature during lamination might be attributed to the increased homogeneity of curing networks.

\section{CONCLUSIONS}

The addition of both $1 \mathrm{~mol} \% \mathrm{Cr}\left(\right.$ acac $_{3}$ and $1 \mathrm{phr}$ $C_{11} Z$ to the TGDDM/DDS epoxy formulation was found to have a synergistic effect on reducing the moisture absorption of the prepared laminate, but not of the neat resin. The synergistic effect was attributed to the separation of the low moisture absorptive TGDDM $/ \mathrm{C}_{11} \mathrm{Z}$-richer network and TGDDM/DDS/ Cr(acac) $)_{3}$-richer network to some extent in the epoxy matrix during the lamination process. When the preheating temperature was decreased during lamination to increase the resin viscosity, the synergistic effect of additives to reduce the moisture absorption of prepared laminates became more pronounced. In addition, the TGDDM/DDS/ $\mathrm{C}_{11} \mathrm{Z} / \mathrm{Cr}(\mathrm{acac})_{3}$ epoxy formulation was not only a low moisture absorptive epoxy formulation for manufacturing the $\mathrm{Gr} / \mathrm{Ep}_{\mathrm{p}}$ laminates, it also provided the cured resin and its prepared laminates with high fracture toughness according to our previous study (9).

\section{ACKTOWLEGMENTS}

Financial support of this work by the National Science Council in Taiwan, R.O.C., from the grant NSC86-2216-E-002-011, is gratefully ackmowledged.

\section{REFERENCES}

1. L. S. Frankel. U.S. Pat. 4,237,242 (1980).

2. J. D. B. Smith, J. Appl. Polym. Sci, 28, 979 (1981).

3. P. V. Reddy, R. Thiagarajan, and M. C. Ratra, J. AppL Polym. Sci. 41, 319 (1990).

4. D. M. Stoakley and A. K. St. Clair, U. S. Pat. $\mathbf{4 , 4 7 3 , 6 7 4}$ (1984).

5. D. M. Stoakley and A. K. St. Clair, J. Appl. Polym. Sci., 31, 225 (1986).

6. Z. F. Nazarova, G. A. Evtushenko, L. A. Palagushkina, and V. V. Artemova, Z. Prikladnoi Khimii, 5o, 2522 (1985).

7. K.-F. Lin, W.-Y. Shu, and T.-L. Wey, Polymer, 34, 277 (1993).

8. K.-F. Lin, W.-Y. Shu, and T.-L. Wey, Polymer, 34, 2161 (1993).

9. K.-F. Lin and W.-H. Wang, Polym. Compos., 16, 269 (1995).

10. A. K. St. Clair, D. M. Stoakley, T. L. St. Clair, and J. J. Singh, U. S. Pat. 4,510,277 (1985).

11. M. S. Heise and G. C. Martin, Macromolecules, 22, 99 (1989).

12. Northrop Materials Specifications NAl-1416 (1978).

13. J. Mijovic and K.-F. Lin, in "Polymer Blends and Composites in Multiphase Systems," C. D. Han, ed. Advances in Chemistry Series 206, p. 323, American Chemical Society, Washington, D. C. (1984). 